\title{
Aptidão agrícola dos solos do estado do Piauí
}

\author{
Karla Nayara Santos de ALMEIDA ${ }^{1 *}$, João Batista Lopes da SILVA², \\ Júlio César Azevedo NÓBREGA ${ }^{3}$, Rafael Felippe RATKE ${ }^{1}$, Kaíse Barbosa de SOUZA ${ }^{4}$
}

\author{
${ }^{1}$ Departamento de Engenharias, Universidade Federal do Piauí, Bom Jesus, PI, Brasil. \\ ${ }^{2}$ Universidade Federal do Sul da Bahia, Campus Paulo Freire, Teixeira de Freitas, BA, Brasil. \\ ${ }^{3}$ Centro de Ciências Agrárias, Ambientais e Biológicas, Universidade Federal do Recôncavo Baiano, Cruz das Almas, BA, Brasil. \\ ${ }^{4}$ Universidade Federal do Espírito Santo, Campus Alegre, Jerônimo Monteiro, ES, Brasil. \\ *E-mail: karlanayara02@yahoo.com.br
}

Recebido em agosto/2018; Aceito em janeiro/2019.

RESUMO: A avaliação da aptidão agrícola das terras estabelece o uso dos recursos naturais de modo a evitar situações de subutilização ou sobreutilização, pois consiste na interpretação das qualidades do ecossistema, baseando-se nas suas limitações para o uso agrícola e nas alternativas e possibilidades de correção ou redução dessas limitações através de diferentes níveis de manejo. Esse trabalho objetivou realizar o mapeamento da aptidão agrícola das terras do estado do Piauí. O método utilizado para a avaliação da aptidão agrícola das terras foi o Sistema de Avaliação da Aptidão Agrícola das Terras. Foram analisados: dados de 120 perfis descritos no Boletim Técnico $N^{\circ} 63$ do Estudo Expedito de Solos no Estado do Piauí elaborado pelo Serviço Nacional de Levantamento e Conservação de Solos da EMBRAPA; a atualização da nomenclatura de perfis de solos descritos no Levantamento Exploratório -Reconhecimento dos solos do Piauí; e o mapa de solos, na escala de 1:500.000, representando a área de estudo e a ocorrência e distribuição das classes de solos predominantes no Estado. A maioria das terras do Piauí possui aptidão agrícola para pastagem plantada (54,57\%), possuindo assim áreas menores para utilização agrícola em usos mais intensivos como lavouras $(26,74 \%)$.

Palavras-chave: avaliação de terras, mapa de aptidão agrícola, planejamento do uso da terra.

\section{Agricultural land sustainability soil of Piauí State, Brazil}

\begin{abstract}
The evaluation of the agricultural potential of the land establishes the use of natural resources to avoid situations of underuse or overuse, it consists in the interpretation of ecosystem qualities based on their limitations for agricultural use and alternative and correction or reduction possibilities these limitations through different management levels. The aims of this work were mapping of the agricultural potential of the Piauí state land soils. The method used to find the agricultural potential of the land was called the System Assessment of Agricultural Lands Fitness. It analyzed: 120 profiles data described in Technical Bulletin No. 63 of Estudo Expedito de Solos no Estado do Piauí prepared by the Serviço Nacional de Levantamento e Conservação de Solos of EMBRAPA; updating the naming soil profiles described in Exploratory survey -recognition of Piauí soil; and the soil map in the scale of 1:500,000, representing the study area and the occurrence and distribution of soil classes prevailing in the state. Most of Piauí land has agricultural potential for planted pastures $(54,57 \%)$, thus having smaller areas for agricultural use in more intensive uses such as crops (26,74\%).
\end{abstract}

Keywords: land evaluation, agricultural suitability map, planning of land use.

\section{INTRODUÇÃO}

A classificação dos solos é de extrema importância para que se possa entender o comportamento de determinada terra mediante o seu uso, permitindo assim estabelecer limites de acordo com as características da mesma, pois o solo possui propriedades intrínsecas que determinam sua aptidão e limitação de uso, as quais são muitas vezes desconsideradas durante as atividades agrícolas.

A avaliação das terras, tendo como preocupação básica prever sua aptidão agrícola, necessita ter, como ponto de partida, um levantamento de solos, o qual é a base para iniciar todo processo de agricultura planejada, fincada em bases conservacionistas.

Essa avaliação da aptidão agrícola das terras consiste na interpretação das qualidades dos ecossistemas baseando-se nas suas limitações para o uso agrícola e nas alternativas e possibilidades de correção ou redução dessas limitações através de diferentes níveis de manejo. O Sistema de Avaliação da Aptidão Agrícola das Terras (SAAAT) de Ramalho Filho; Beek (1995) foi desenvolvido para ser utilizado em trabalho de interpretação de levantamentos de solos e avalia alternativas de utilização tais como lavouras, pastagem plantada, silvicultura e/ou pastagem natural e preservação da flora e fauna, preservando desta forma os solos, pois evita o uso inapropriado.

O Piauí tem vivenciado uma ocupação acelerada do Cerrado, por meio da implementação de grandes projetos para a produção de grãos como a soja (AGUIAR; MONTEIRO, 2005). Essa expansão da fronteira agrícola contribui para o crescimento do Brasil e integração econômica da região, no entanto, também contribui para a degradação de ecossistemas através da substituição da cobertura natural por pastagens e lavouras (PLÁ, 2011), devendo assim ocorrer um equilíbrio entre a expansão agrícola e a preservação/conservação da 
cobertura vegetal natural. Para isto faz-se necessário conhecer e adequar o uso das terras no território piauiense, através de informações sobre a caracterização das áreas de acordo com sua aptidão, a qual pode ser representada por mapas que determinem a classificação desses solos, distribuição e potencial agrícola.

Assim, neste contexto, objetivou-se com esse trabalho realizar o mapeamento da aptidão agrícola das terras do estado do Piauí, a fim de oferecer uma visão sinóptica sobre o potencial agrícola de seus solos.

\section{MATERIAL E MÉTODOS}

\subsection{Descrição e localização da área de estudo}

O trabalho foi realizado no Estado do Piauí, localizado na região Nordeste do Brasil, o qual apresenta uma área de $251.578 \mathrm{~km}^{2}, 2,95 \%$ do total do território nacional. Encontrase entre os paralelos $02^{\circ} 44^{\prime} 49^{\prime \prime} \mathrm{S}$ e $10^{\circ} 55^{\prime} 41^{\prime \prime} \mathrm{S}$ e entre os meridianos de $40^{\circ} 22^{\prime} 12^{\prime \prime} \mathrm{O}$ e $45^{\circ} 59^{\prime} 42^{\prime \prime} \mathrm{O}$.

O estado do Piauí está situado numa zona de transição entre o Nordeste semiárido e a Amazônia úmida, encontrandose nessa zona de contato entre os três principais biomas brasileiros - cerrado, caatinga e floresta amazônica, fazendo parte de uma zona de transição balanceada, sem os rigores climáticos que caracterizam cada uma separadamente, o que justifica as diferenças climáticas entre suas regiões.

O relevo do Piauí é predominantemente regular com mais de $90 \%$ de sua área situada em altitude inferior a $600 \mathrm{~m}$. Ao longo das fronteiras com o Ceará, Pernambuco e Bahia, encontram-se as maiores altitudes da região, situadas em torno de $900 \mathrm{~m}$.

\subsection{Levantamento de dados}

Os dados utilizados no trabalho foram: o Boletim Técnico $\left(\mathrm{N}^{\circ} 63\right)$ - do Estudo Expedito de Solos no Estado do Piaú elaborado pelo Serviço Nacional de Levantamento e Conservação de Solos (SNLCS) da Embrapa, (JACOMINE,1986); a atualização da nomenclatura de perfis de solo descritos no Levantamento Exploratório Reconhecimento dos solos do Piauí feita por Ibiapina et al. (2007); e o mapa de solos, na escala de 1:500.000, representando a área de estudo a ocorrência e distribuição das classes de solos predominantes no Estado.

De modo auxiliar, também foram utilizadas a delimitação do Semiárido Brasileiro determinada pela Portaria Interministerial $\mathrm{N}^{\circ} 01$ de 09 de março de 2005, o Atlas Geográfico do Piauí e as cartas do Instituto Brasileiro Geografia e Estatística.

Foram analisados dados de 120 perfis descritos no Boletim $\mathrm{N}^{\circ}$ 63, onde interpretaram-se o levantamento pedológico de cada perfil, avaliando sua descrição morfológica e análises físicas e químicas, bem como as várias características físico ambientais dispostas no documento, tais como: solo, relevo, clima e vegetação. Baseando-se na metodologia de Ramalho Filho; Beek (1995) estas informações foram utilizadas para obter o grau de limitação correspondente a cada feição representativa de solo e por seguinte realizar a classificação da aptidão agrícola.

Para fins de atualização da classificação dos solos, os perfis foram reclassificados até o quarto nível categórico (IBIAPINA et al.,2007), conforme o Sistema Brasileiro de Classificação de Solos (EMBRAPA, 2006) e novamente analisados para serem utilizados na confecção do mapa de aptidão, até o segundo nível categórico, conforme o Sistema Brasileiro de Classificação de Solos (EMBRAPA, 2013).

\subsection{Sistema de Avaliação da Aptidão Agrícola das Terras}

O método utilizado para a avaliação da aptidão agrícola das terras foi o de Ramalho Filho; Beek (1995), denominado Sistema de Avaliação da Aptidão Agrícola das Terras, elaborado com base em experiências brasileiras para a interpretação de levantamento de solos e em trabalhos validados internacionalmente. Tomando como base práticas agrícolas ao alcance da maioria dos agricultores, foram considerados três níveis de manejo: A) baixo nível tecnológico; B) médio nível tecnológico; e C) alto nível tecnológico. Para permitir a representação desses diferentes tipos de uso, conforme os níveis de manejo, o sistema de classificação foi estruturado em grupos, subgrupos e classes de aptidão.

Foram considerados cinco fatores limitantes à utilização das terras: (i) deficiência de fertilidade; (ii) deficiência de água; (iii) excesso de água; (iv) susceptibilidade à erosão; e (v) impedimentos à mecanização. Estes fatores limitantes foram avaliados a partir de atributos do solo, do relevo e do clima, com base nas fases de vegetação natural, sendo que, para a análise das condições agrícolas das terras, tomou-se hipoteticamente, como referência, um solo que não apresentasse problemas de limitação. Assim, para cada um desses fatores citados foram admitidos, de acordo com os critérios definidos na metodologia utilizada os seguintes graus de limitação: nulo (N), ligeiro (L), moderado (M), forte (F) e muito forte (MF).

Assim, foram avaliados os graus de limitação dos 120 perfis de solos, para depois realizar uma estimativa da viabilidade de melhoramento das limitações de acordo com quatro classes de melhoramento das condições agrícolas das terras. No entanto, alguns fatores limitantes não foram passíveis de melhoramento, como é o caso da deficiência de água, uma vez que a irrigação não se inclui entre as práticas de melhoramento previstas, e o impedimento à mecanização, que só é considerado relevante no nível de manejo $\mathrm{C}$.

A representação dos grupos de aptidão foi feita com algarismos de 1 a 6 , onde as limitações aumentam do grupo 1 para o grupo 6, diminuindo, consequentemente, as alternativas de uso e a intensidade com que as terras podem ser utilizadas. Subgrupos foram adotados para atender às variações que se verificam dentro do grupo. As classes expressam a aptidão agrícola das terras para um determinado tipo de utilização (lavouras, pastagem plantada, silvicultura e pastagem natural) com nível de manejo definido, dentro do subgrupo de aptidão, refletem ainda o grau de intensidade das limitações, com base no boletim da FAO (1976) em: classe boa, classe regular, classe restrita e classe inapta (Figura 1).

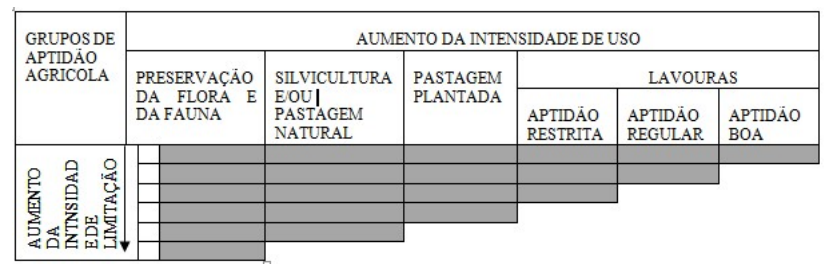

Figura 1. Alternativas de utilização das terras de acordo com os grupos de aptidão agrícola. Fonte: Ramalho Filho; Beek (1995).

Figure 1. Land use alternatives according to the agricultural suitability groups. Source: Ramalho Filho; Beek (1995). 
Para determinar as classes de aptidão agrícola e, por conseguinte, os grupos e subgrupos, foi feito um comparativo entre os graus de limitação atribuídos às terras e os estipulados nos Quadros-Guia de Avaliação da Aptidão Agrícola, elaborados para atender às regiões de clima tropical úmido e semiárido, além possibilidade de melhoramento das condições naturais das terras, mediante a adoção dos níveis de manejo $\mathrm{B}$ e C. Para determinar o clima do município onde se encontrava o perfil analisado foi utilizado a delimitação do semiárido brasileiro determinada pela Portaria interministerial $\mathrm{N}^{\mathrm{o}} 01 \mathrm{de}$ 09 de março de 2005.

A classificação da aptidão agrícola foi feita, portanto, com base na viabilidade de melhoramento dos graus de limitação das condições agrícolas das terras. No caso do nível de manejo A, a classificação foi feita de acordo com as condições naturais da terra. A classe de aptidão agrícola, de acordo com os diferentes níveis de manejo, foi obtida em função do grau limitativo mais forte, referente a qualquer um dos fatores que influenciam a sua utilização agrícola. As terras consideradas inaptas para lavouras tiveram suas possibilidades analisadas para usos menos intensivos (pastagem plantada, silvicultura ou pastagem natural), enquanto as terras classificadas como inaptas para os diversos tipos de utilização, foram indicadas para preservação da flora e da fauna.

A simbologia adotada teve como objetivo principal permitir a apresentação, em um só mapa, da classificação da aptidão agrícola das terras para diversos tipos de utilização, sob três níveis de manejo. Nessa representação foram utilizados, em conjunto, números e letras. Os algarismos de 1 a 6, como anteriormente mencionado, referem-se aos grupos de aptidão agrícola e indicam o tipo de utilização mais intensivo permitido. As letras que acompanham os algarismos são indicativas das classes de aptidão, de acordo com os níveis de manejo, como indicação dos diferentes tipos de utilização. As letras A, B e C referem-se à lavoura; P à pastagem plantada,
$\mathrm{N}$ à pastagem natural e $\mathrm{S}$ à Silvicultura e podem aparecer nos subgrupos em maiúsculas, minúsculas ou minúsculas entre parênteses, representando, respectivamente, a classe de aptidão boa, regular ou restrita para o tipo de utilização considerado (Tabela 1). A indicação da classe inapta, ao contrário das demais, não é representada por símbolos, mas sim, feita pela ausência das letras no tipo de utilização considerado. Para a representação cartográfica dos grupos, subgrupos e classes de aptidão agrícola das terras foi utilizado um sistema com 6 cores, determinando para cada grupo uma cor básica, baseado na metodologia de Ramalho Filho; Beek (1995).

\subsection{Mapa final de aptidão agrícola}

O mapa final de aptidão agrícola foi obtido pelo cruzamento das informações oriundas do mapa de solo do Piauí, juntamente com os perfis analisados e as classes de aptidão geradas através do sistema de avaliação de aptidão agrícola estudado. As etapas de confecção do mapa foram realizadas no software de SIG ArcGIS 10.

A posição geográfica dos perfis classificados foi associada com as formações de solo dispostas no mapa do IBGE e após essa localização geográfica fez-se a associação das aptidões geradas a toda área abrangente ao mesmo tipo de solo, a qual está delimitada no mapa. Ao final foi confeccionado um mapa de aptidão preconizado com a metodologia proposta por Ramalho Filho; Beek (1995) o qual utiliza o uso mais intensivo possível.

\section{RESULTADOS}

Após a avaliação dos perfis pedogenéticos constituintes no Boletim Técnico ( $\mathrm{N}^{\circ}$ 63) do Estudo Expedito de Solos no Estado do Piauí, utilizando-se a metodologia de Ramalho Filho; Beek (1995) pode-se encontrar 20 subgrupos incluídos em 5 grupos: Grupos 2, 3, 4,5 e 6 (Tabela 2).

Tabela 1. Simbologia correspondente às classes de aptidão agrícola das terras.

Table 1. Symbology corresponding to the agricultural aptitude classes of the lands.

\begin{tabular}{lcccccc}
\hline \multirow{2}{*}{ Classe de Aptidão Agrícola } & \multicolumn{7}{c}{ Lavouras } & \multicolumn{2}{c}{ Pastagem Plantada } & Silvicultura & Pastagem Natural \\
\cline { 2 - 7 } & \multicolumn{2}{c}{ Nível de Manejo } & Nível de Manejo B & Nível de Manejo B & Nível de Manejo A \\
\cline { 2 - 8 } & A & B & C & P & S & N \\
BOA & a & b & c & p & $\mathrm{s}$ & $\mathrm{n}$ \\
RESTRITA & (a) & (b) & (c) & (p) & (s) & (n) \\
INAPTA & - & - & - & - & - & - \\
\hline
\end{tabular}

\section{DISCUSSÃO}

Apenas $26,74 \%$ da região piauiense apresenta aptidão natural para o cultivo de lavouras em algum nível de manejo, sendo que $23,10 \%$ refere-se a aptidão regular e 3,64\% a aptidão restrita, considerando assim, a existência de uma pequena extensão de terras aptas à implantação e condução desse uso mais intensivo.

O predomínio na área de estudo é de solos aptos para pastagem plantada, com um total de $54,57 \%$ da área do estado, isto devido à grande variação climática que ocorre na extensão do território piauiense, a qual direciona a minimização de usos mais intensivos devido a escassez hídrica em algumas áreas, tornando esse, um fator limitante na maioria dos perfis estudados, pois, de acordo com Araújo; Araújo (2009), a condição climática é considerada uma variável determinante para a riqueza da biodiversidade de biomas, caracterizando suas estações secas e chuvosas e influenciando na sua produtividade. A aptidão para pastagem natural e/ou silvicultura encontra-se em $15,34 \%$ do território piauiense, sendo este, o uso agrícola menos intensivo. Esse resultado é semelhante ao verificado por Araújo et al., (2013) em uma microrregião de Mossoró-RN, no qual foi determinado que $17,70 \%$ da área possui esse tipo de aptidão. $\mathrm{O}$ estado possui ainda, 3,34\% de suas terras sem aptidão agrícola, sendo essas, referentes a áreas de proteção permanente, representadas principalmente por matas ciliares.

Dentre os 120 perfis estudados, encontram-se 11 classes de solos, as quais foram organizadas até o segundo nível categórico e relacionadas com as classes de aptidão pertencentes a cada tipo de solo, indicando ainda os limitantes que ocasionaram a classificação final da aptidão das terras (Tabela 3).

Os Argissolos evidenciaram uma variação entre seu uso para lavouras e a utilização apenas para pastagem plantada, 
relacionando essa diferença, principalmente, à localização dos perfis estudados que demonstram uma extensa variação climática. A própria característica de baixa fertilidade e considerável pedregosidade do solo foi decisiva na classificação do potencial de uso das terras, dificultando assim a mecanização e sua utilização com alto nível tecnológico.

Tabela 2. Correspondência entre as classes de aptidão e a área territorial e percentagem do estado do Piauí

Table 2. Correspondence between the fitness classes and the territorial area and percentage of the state of Piauí.

\begin{tabular}{|c|c|c|c|}
\hline $\begin{array}{c}\text { Classe de } \\
\text { Aptidão }\end{array}$ & Legenda no mapa & Área $\left(\mathrm{km}^{2}\right)$ & $\%$ \\
\hline $\begin{array}{c}2 \mathrm{abc} \\
2 \mathrm{ab}(\mathrm{c}) \\
2(\mathrm{a}) \mathrm{bc} \\
2(\mathrm{a}) \mathrm{b}(\mathrm{c}) \\
2 \mathrm{n}(\mathrm{b}) \mathrm{c} \\
2 \mathrm{nPc}\end{array}$ & $\begin{array}{l}\text { Aptidão regular para } \\
\text { lavouras em pelo } \\
\text { menos um dos níveis } \\
\text { de manejo } \mathrm{A}, \mathrm{B} \text { ou } \mathrm{C} \text {. }\end{array}$ & $60.950,39$ & $23,10 \%$ \\
\hline $\begin{array}{c}3(\mathrm{a})(\mathrm{b})(\mathrm{c}) \\
3(\mathrm{a})(\mathrm{b}) \\
3(\mathrm{a}) \mathrm{p} \\
3(\mathrm{a})(\mathrm{p}) \\
3 \mathrm{n}(\mathrm{b}) \\
3 \mathrm{nP}(\mathrm{c}) \\
\end{array}$ & $\begin{array}{l}\text { Aptidão restrita para } \\
\text { lavouras em pelo } \\
\text { menos um dos níveis } \\
\text { de manejo } \mathrm{A}, \mathrm{B} \text { ou } \mathrm{C} \text {. }\end{array}$ & $9.616,39$ & $3,64 \%$ \\
\hline $\begin{array}{c}\mathrm{nP} \\
4 \mathrm{~N}(\mathrm{p}) \\
4 \mathrm{n}(\mathrm{p}) \\
\end{array}$ & $\begin{array}{l}\text { Aptidão boa e restrita } \\
\text { para pastagem } \\
\text { plantada. }\end{array}$ & $143.996,53$ & $54,57 \%$ \\
\hline $\begin{array}{c}5 \mathrm{Ns} \\
5 \mathrm{~ns} \\
5 \mathrm{~N} \\
5 \mathrm{n} \\
5(\mathrm{n}) \\
\end{array}$ & $\begin{array}{l}\text { Aptidão boa, regular } \\
\text { ou restrita para } \\
\text { silvicultura e/ou } \\
\text { pastagem natural. }\end{array}$ & $40.482,14$ & $15,34 \%$ \\
\hline 6 & $\begin{array}{l}\text { Áreas de Proteção } \\
\text { Permanente (Mata } \\
\text { Ciliares) ou Inaptas a } \\
\text { agricultura }\end{array}$ & $8.812,26$ & $3,34 \%$ \\
\hline
\end{tabular}

Delarmelinda (2014), ao avaliar a aptidão agrícola do estado do Acre, encontrou indicação da aptidão restrita para pastagem plantada em Argissolos em função do grau de susceptibilidade à erosão e da deficiência de fertilidade. Brighentiet al.(2012) afirmam que a grande maioria dos argissolos encontrados no Brasil possui baixa fertilidade natural, com predomínio de caulinita na fração argila, afetando assim potencial agrícola.

Para os Cambissolos foi determinada aptidão regular para lavouras e restrita para pastagem plantada, pois possuem boas características de fertilidade natural e utilização de maquinários, já que os perfis estudados situam-se em relevos planos, tendo assim, como fator limitante a baixa ocorrência de chuvas. Em ambientes de relevos mais declivosos, esses solos apresentam fortes limitações para o uso agrícola relacionados à mecanização e à alta suscetibilidade aos processos erosivos (DELARMELINDA,2014). Rampim, et al (2012) identificam em seu estudo glebas de Cambissolos com maiores limitações ao uso intensivo de cultivo, demonstrando que a variação de declividade existente na área pode interferir na sua aptidão agrícola.

A aptidão agrícola dos Chernossolos na região piauiense para pastagem plantada foi condicionada pela baixa disponibilidade de água e alta incidência de pedregosidade causando impedimentos à mecanização. Este fato também foi constatado por Dalmolin et al. (2003) que encontraram nessa classe de solo o horizonte superficial caracterizado pela excessiva pedregosidade, demonstrando que, apesar de apresentarem uma alta fertilidade natural associada principalmente aos altos teores de cálcio, magnésio e matéria orgânica, como também observado no presente estudo, a alta pedregosidade inviabiliza manejos mais intensivos nesses solos.

Tabela 3. Classes de aptidão dos solos e seus principais fatores limitantes.

Table 3. Classes of soil suitability and its main limiting factors.

\begin{tabular}{|c|c|c|}
\hline $\begin{array}{l}\text { Classes de } \\
\text { solos }\end{array}$ & $\begin{array}{l}\text { Classes de } \\
\text { aptidão }\end{array}$ & Limitantes \\
\hline $\begin{array}{l}\text { Argissolo } \\
\text { amarelo }\end{array}$ & $\begin{array}{l}2(a) b c \\
3(a) p \\
4 N(p) \\
\end{array}$ & \multirow[b]{2}{*}{$\begin{array}{l}\text { Baixa disponibilidade hídrica, } \\
\text { baixa fertilidade e impedimento } \\
\text { a mecanização. }\end{array}$} \\
\hline $\begin{array}{l}\text { Argissolo } \\
\text { vermelho- } \\
\text { amarelo }\end{array}$ & $\begin{array}{c}2 a b c \\
2(a) b c \\
4 N(p) \\
4 n(p) \\
4 n\end{array}$ & \\
\hline $\begin{array}{l}\text { Argissolo } \\
\text { acinzentado }\end{array}$ & $4 \mathrm{n}(\mathrm{p})$ & Baixa disponibilidade hídrica \\
\hline $\begin{array}{l}\text { Cambissolo } \\
\text { háplico }\end{array}$ & $\begin{array}{l}2(a) b(c) \\
4 N(p)\end{array}$ & Baixa disponibilidade hídrica \\
\hline $\begin{array}{l}\text { Chernossolos } \\
\text { argilúvico }\end{array}$ & $\begin{array}{l}4 \mathrm{n}(\mathrm{p}) \\
4 \mathrm{~N}(\mathrm{p})\end{array}$ & $\begin{array}{l}\text { Baixa disponibilidade hídrica e } \\
\text { impedimento a mecanização. }\end{array}$ \\
\hline $\begin{array}{l}\text { Gleissolo } \\
\text { háplico }\end{array}$ & $5(\mathrm{n})$ & $\begin{array}{l}\text { Baixa fertilidade e impedimento } \\
\text { a mecanização. }\end{array}$ \\
\hline $\begin{array}{l}\text { Latossolo } \\
\text { amarelo }\end{array}$ & $\begin{array}{l}2(a) b c \\
2 n(b) c \\
4 N(p) \\
4 n(p)\end{array}$ & \multirow{3}{*}{$\begin{array}{l}\text { Baixa fertilidade e baixa } \\
\text { disponibilidade hídrica }\end{array}$} \\
\hline $\begin{array}{l}\text { Latossolo } \\
\text { vermelho }\end{array}$ & $\begin{array}{l}2(a) b c \\
4 N(p) \\
4 n(p)\end{array}$ & \\
\hline $\begin{array}{l}\text { Latossolo } \\
\text { vermelho- } \\
\text { amarelo }\end{array}$ & $\begin{array}{l}2 \mathrm{nPc} \\
4 \mathrm{~N}(\mathrm{p}) \\
4 \mathrm{n}(\mathrm{p})\end{array}$ & \\
\hline $\begin{array}{l}\text { Luvissolo } \\
\text { hipocrômico }\end{array}$ & $4 \mathrm{~N}(\mathrm{p})$ & $\begin{array}{l}\text { Baixa disponibilidade hídrica e } \\
\text { impedimento a mecanização. }\end{array}$ \\
\hline $\begin{array}{l}\text { Neossolo } \\
\text { flúvico }\end{array}$ & $\begin{array}{c}2 \mathrm{ab}(\mathrm{c}) \\
3(\mathrm{a})(\mathrm{b})(\mathrm{c}) \\
4 \mathrm{~N}(\mathrm{p})\end{array}$ & $\begin{array}{l}\text { Baixa disponibilidade hídrica e } \\
\text { imperfeita drenagem. }\end{array}$ \\
\hline $\begin{array}{l}\text { Neossolo } \\
\text { litólico }\end{array}$ & $\begin{array}{l}5 \mathrm{~N} \\
5 \mathrm{n}\end{array}$ & $\begin{array}{l}\text { Baixa disponibilidade hídrica e } \\
\text { impedimento a mecanização. }\end{array}$ \\
\hline $\begin{array}{l}\text { Neossolo } \\
\text { quartzarênico }\end{array}$ & $\begin{array}{c}5 \mathrm{Ns} \\
5 \mathrm{~ns}\end{array}$ & $\begin{array}{l}\text { Baixa disponibilidade hídrica, } \\
\text { baixa fertilidade e impedimento } \\
\text { a mecanização. }\end{array}$ \\
\hline $\begin{array}{l}\text { Neossolo } \\
\text { regolítico }\end{array}$ & $5 \mathrm{Ns}$ & $\begin{array}{l}\text { Baixa disponibilidade hídrica e } \\
\text { impedimento a mecanização }\end{array}$ \\
\hline $\begin{array}{l}\text { Nitossolo } \\
\text { háplico }\end{array}$ & $\begin{array}{l}4 \mathrm{~N}(\mathrm{p}) \\
4 \mathrm{n}(\mathrm{p})\end{array}$ & $\begin{array}{l}\text { Baixa disponibilidade hídrica, } \\
\text { impedimento a mecanização e } \\
\text { baixa fertilidade. }\end{array}$ \\
\hline $\begin{array}{l}\text { Nitossolo } \\
\text { vermelho }\end{array}$ & $3 \mathrm{n}(\mathrm{b})$ & $\begin{array}{l}\text { Baixa disponibilidade hídrica e } \\
\text { impedimento a mecanização. }\end{array}$ \\
\hline $\begin{array}{l}\text { Planossolo } \\
\text { háplico }\end{array}$ & $\begin{array}{l}4 \mathrm{~N}(\mathrm{p}) \\
4 \mathrm{n}(\mathrm{p})\end{array}$ & Baixa disponibilidade hídrica \\
\hline $\begin{array}{l}\text { Planossolo } \\
\text { nátrico }\end{array}$ & $\begin{array}{c}4 \mathrm{nP} \\
4 \mathrm{n}(\mathrm{p})\end{array}$ & \\
\hline $\begin{array}{l}\text { Plintossolo } \\
\text { argilúvico }\end{array}$ & $\begin{array}{c}4 \mathrm{n}(\mathrm{p}) \\
2(\mathrm{a}) \mathrm{b}(\mathrm{c}) \\
3(\mathrm{a})(\mathrm{b}) \\
3 \mathrm{nP}(\mathrm{c}) \\
4 \mathrm{~N}(\mathrm{p})\end{array}$ & $\begin{array}{l}\text { Baixa disponibilidade hídrica, } \\
\text { baixa fertilidade, impedimento a } \\
\text { mecanização e má drenagem }\end{array}$ \\
\hline $\begin{array}{l}\text { Plintossolo } \\
\text { pétrico }\end{array}$ & $\begin{array}{l}3(\mathrm{a})(\mathrm{p}) \\
4 \mathrm{n}(\mathrm{p})\end{array}$ & $\begin{array}{l}\text { Baixa fertilidade e impedimento } \\
\text { a mecanização. }\end{array}$ \\
\hline $\begin{array}{l}\text { Vertissolo } \\
\text { ebânico }\end{array}$ & $4 \mathrm{~N}(\mathrm{p})$ & Baixa disponibilidade hídrica. \\
\hline
\end{tabular}


Os Gleissolos apresentaram limitações referentes à fertilidade, devido grande incidência de sódio, além de serem solos mal ou muito mal drenados em condições naturais, limitando-os ao uso agrícola apenas para pastagem natural. Assim, como esse trabalho, quantidades mais elevadas de sódio em gleissolos háplicos foram encontradas por Guimarães et al. (2013), demonstrando que esses solos apresentam restrições, geralmente, relacionadas à toxidez na maioria das plantas, causadas por teores elevados de alumínio, sódio e enxofre.

Os Latossolos ocupam uma extensa área no território do Piauí e a variação das classes de aptidão entre os Latossolos ocorreu desde sua utilização, de forma regular para lavouras, até seu uso apenas para pastagem plantada, o que pode ser justificado devido à baixa disponibilidade hídrica em algumas regiões do estado além de sua baixa fertilidade, corroborando com os resultados encontrados por Delarmelinda (2014).

Os Luvissolos, apesar de conferir uma alta fertilidade natural, evidenciaram uma utilização apenas para pastagem plantada devido uma ligeira pedregosidade aliada a uma baixa disponibilidade hídrica, semelhante ao encontrado no trabalho de Medeiros et al.(2013), os quais verificaram no Luvissolo elevados teores de calhaus e cascalhos apesar de possuir altos teores de potássio e uma alta saturação por bases.

Já na aptidão dos Neossolos, os quais são solos pouco evoluídos, houve predominância de sua utilização para pastagem natural, demonstrando impedimentos gerados a partir de características específicas desses solos, como é o caso dos Neossolos quartzarênicos que possuem uma enorme restrição causada pela textura arenosa a qual ocasiona uma baixa retenção de umidade, inviabilizando o uso de um manejo tecnológico e consequentemente seu uso para lavouras (EMBRAPA, 2013). Os Nitossolos obtiveram classes com uso restrito a lavoura e pastagem plantada, evidenciando problemas relacionados principalmente com disponibilidade hídrica e impedimento a mecanização devido à presença de pedregosidade. Em contrapartida, Rauber et al. (2012) ao estudarem um Nitossolo Vermelho observaram na estrutura desse solo condições físicas favoráveis, tais como a densidade do solo, resistência à penetração abaixo de valores críticos, e estabilidade de agregados elevada.

$\mathrm{Na}$ classificação, os Planossolos, não foram adequados a utilização para usos mais intensivos do que pastagem plantada, devido a questões, má drenagem e pela presença excessiva de sódio no caso dos planossolos nátricos. Em seu estudo Matos et al. (2015) caracterizam os planossolos nátricos como solos densos e pouco porosos devido à dispersão de argila causada pelo sódio presente no horizonte Btn, possuindo ainda uma fertilidade mediana, com teores de sódio e magnésio elevados.

Nas áreas correspondentes aos Plintossolos, além da baixa disponibilidade hídrica, apresentou-se também, baixa fertilidade natural e impedimento à mecanização. Os Plintossolos podem se limitantes ao desenvolvimento de culturas devido seus baixos teores nutricionais, sendo, portanto, considerado um solo com sérias restrições edáficas, dentre elas, as restrições de drenagem e/ou presença de elevada quantidade de cascalhos e pedregosidade (EMBRAPA, 2013)

Assim como os Plintossolos, a aptidão agrícola em Vertissolos teve como fator limitante a baixa disponibilidade hídrica, além de exibirem sérias limitações quanto ao uso de máquinas no período chuvoso, devido sua característica de expansão e contração e ainda possuírem baixa infiltração de água e drenagem lenta, favorecendo o encharcamento destes solos e sendo portanto, indicado para pastagem plantada apesar de possuir uma boa fertilidade natural (EMBRAPA, 2013).

Partindo do princípio da avaliação geral da aptidão pelo método proposto, o qual se baseia na classificação das terras para os três níveis de manejo, pode-se observar no mapa de aptidão agrícola das terras (Figura 2) a distribuição da aptidão agrícola dos solos do Piauí, na qual houve uma variação de classes de aptidão motivadas por vários fatores, dentre os principais encontram-se: a variação climática, que direcionou à algumas regiões um uso menos intensivo dos solos, independentemente do nível de manejo utilizado e ainda as características próprias desses solos, como a baixa fertilidade que afeta diretamente agricultores em nível de manejo A e a ocorrência de pedregosidade que prejudica o desempenho da agricultura para os níveis de manejo mais tecnificados.

O mapa de aptidão agrícola das terras do Piauí (Figura 2) é condizente com a atividade agrícola de produção de grãos no Estado, principalmente com o cultivo da soja, a qual está bastante concentrada no sudoeste piauiense, nos municípios de Baixa Grande do Ribeiro, Uruçuí, Ribeiro Gonçalves, Santa Filomena e Bom Jesus (IBGE, 2015) estando estes, inseridos na faixa em que se determina a aptidão para lavouras. Leal \& França (2010) analisando um recorte temporal de 1998 a 2008, afirmam que os maiores produtores de soja no Piauí são os municípios de Baixa Grande do Ribeiro, Bom Jesus, Ribeiro Gonçalves e Uruçuí, ainda determinam que a partir do ano de 2007, alguns municípios como Antônio Almeida, Alvorada do Gurgueia, Currais, Landri Sales, Manoel Emídio, Monte Alegre do Piauí, Porto Alegre do Piauí e Piracuruca, que não eram produtores, começaram a produzir essa cultura, podendo observar no mapa que tais municípios citados também encontram-se em áreas aptas à cultivos mais intensivos.

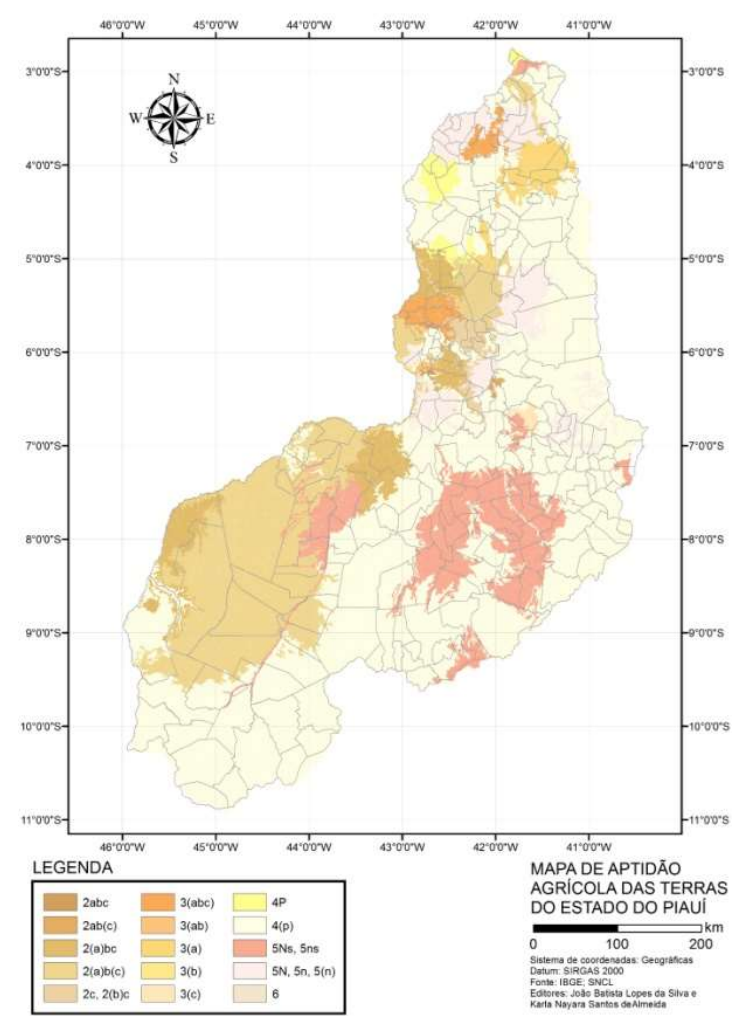

Figura 2. Mapa de aptidão agrícola do Estado do Piauí incluindo os três tipos de manejo.

Figure 2.Map of agricultural aptitude of the State of Piauí including the three types of management. 


\section{CONCLUSÕES}

O estado do Piauí possui em sua maioria solos com aptidão para pastagem plantada $(54,57 \%)$, apesar da ocorrência de áreas com aptidões para usos mais intensivos, mesmo que de forma regular $(23,10 \%)$ e restrita $(3,64 \%)$, tendo ainda, $15,34 \%$ de sua área destinada ao uso para pastagem natural e/ou silvicultura.

As áreas inaptas para o cultivo agrícola estão condicionadas em grande parte, por áreas de preservação permanente, principalmente áreas de mata ciliar (3,34\%).

A diversidade climática interfere diretamente no uso dos solos piauienses, muitas vezes limitando-os à utilizações menos intensivas, independentemente do nível de manejo utilizado.

As características físicas e químicas dos solos evidenciaram limitações para os três níveis de manejo, sendo a baixa fertilidade o maior limitante para o manejo com baixa tecnologia e o impedimento a mecanização, gerado principalmente pela ocorrência de pedregosidade, o maior limitante para manejos com níveis mais tecnológicos.

\section{REFERÊNCIAS}

AGUIAR, T. de J. A.; MONTEIRO, M. S. L. Modelo agrícola e desenvolvimento sustentável: a ocupação do cerrado piauiense. Ambiente \& Sociedade, Campinas, v. 8, n. 2, p. 161-178, 2005. DOI: http://dx.doi.org/10.1590/S1414753X2005000200009

ARAÚJO, M. R. S. de; ARAUJO, J. L. L. A expansão da fronteira agrícola nos cerrados piauienses e a reorganização do espaço do município de Bom Jesus: um estudo de caso. In: Encuentro de Geógrafos da América Latina, 12., 2009, Montevidéu. Anais... Montevidéu, 2009.

ARAÚJO, J. M. S.; OLIVEIRA, H. A. de; BEZERRA, H. N.; SILVA, P. C. M. da. Determinação da aptidão agrícola da microrregião de Mossoró-RN. Engenharia na Agricultura, Viçosa - MG, v. 21, n. 2, p. 148-158, 2013. DOI: https://dx.doi.org/10.13083/reveng.v21i2.330

BRIGHENTI, I.; ALMEIDA, J. A. de; HOFER, A. Mineralogia e gênese de argissolos das Serras do Tabuleiro/Itajaí, Estado de Santa Catarina. Revista Brasileira de Ciência do Solo [online], Viçosa, v. 36, n. 4, p. 1057-1072, 2012. DOI: http://dx.doi.org/10.1590/S0100-06832012000400001

DALMOLIN, R. S. D.; PEDRON, F. A.; AZEVEDO, A. C.; ZAGO, A. Levantamento semidetalhado de solos da microbacia do arroio Lino-Município de Agudo (RS). Santa Maria: FATEC/UFSM, 2003. 84 p. (Relatório Técnico Programa RS-Rural/SAA-RS)

DELARMELINDA, E. A.; WADT, P. G. S.; ANJOSM L. H. C.; MASUTTI, C. S. M.; SILVA, E. F. da; SILVA, M. B. e; COELHO, R. M.; SILVA, L. M. da; SHIMIZU, S. H.; COUTO, W. H. do. Aplicação de sistemas de avaliação da aptidão agrícola das terras em solos do Estado do Acre, Amazônia. Revista Biota Amazônia, Macapá, v. 4, n. 2, p. 87-95, 2014. DOI: http://dx.doi.org/10.18561/21795746/biotaamazonia.v4n2p87-95

EMBRAPA _EMPRESA BRASILEIRA DE PESQUISA AGROPEC $\bar{C}$ UÁRIA. Sistema brasileiro de classificação de solos. 3. ed. Brasília-DF: Centro Nacional de Pesquisa de Solos, 2013. 353 p.

EMBRAPA_EMPRESA BRASILEIRA DE PESQUISA AGROPECUÁRIA. Sistema brasileiro de classificação de solos. 2. ed. Brasília-DF: Centro Nacional de Pesquisa de Solos, 2006. 306 p.

FAO FOOD AND AGRICULTURE ORGANIZATION OF THE UNITED NATIONS. A Framework for Land Evaluation. Rome: FAO, 1976. (FAO Soils Bulletim, 32). GUIMARÃES, S. T.; LIMA, H. N.; TEIXEIRA, W. G.; NEVES JUNIOR, A. F.; SILVA, F. W. R.; MACEDO, R. S.; SOUZA, K. W. Caracterização e classificação de gleissolos da várzea do rio Solimões (Manacapuru e Iranduba), Amazonas, Brasil. Revista Brasileira Ciência do Solo, Viçosa, v. 37, n. 2, p. 317-326, 2013. DOI: http://dx.doi.org/10.1590/S0100-06832013000200003

IBIAPINA, T. V. B.; SALVIANO, A. A. C.; NOBREGA, J. C. A.; ARAÚJO, A. S. F. de. Atualização da nomenclatura de 100 perfis de solo do Levantamento ExploratórioReconhecimento do estado do Piauí. In: Congresso Brasileiro de Ciência do Solo, 31., 2007, Gramado, RS. Anais..., Rio Grande do Sul, 2007.

IBGE INSTITUTO BRASILEIRO DE GEOGRAFIA E ESTATÍSTICA. Sistema IBGE de Recuperação Automática-SIDRA. Disponível em: $<$ http://www.sidra.ibge.gov.br/>. Acesso em: 16 de set. 2015.

JACOMINE, P. K. T. Levantamento Exploratório Reconhecimento de Solos do Estado do Piauí, Rio de Janeiro. Rio de Janeiro: EMBRAPA - SNLCS / SUDENE, 1986. 782 p.

LEAL, M. N.; FRANÇA, V. L. A. Reestruturação da produção agrícola e organização do espaço agrário piauiense: o agronegócio da commodity soja. Boletim Goiano de Geografia, Goiânia, v. 30, n. 2, p. 13-28, 2010.

MATOS, C. H. L. de; NASCIMENTO, O. P. R. R; ALVES, R. N.; ALMEIDA, K. M. Gênese e morfologia das principais classes de solo encontradas nas regiões central e norte de Roraima. Revista de Biologia e Ciências da Terra, São Cristóvão, v. 15, n. 2, p. 53-58, 2015.

MEDEIROS, B. V. V. de; MEDEIROS, L. C. de; ERNESTO SOBRINHO, F.; GURGEL, M. T. Caracterização física e química de solos sob pecuária bovina no semiárido do Seridó-RN. Revista ACSA- Agropecuária Científica no Semiárido. v. 9, n. 4, p. 08-16, 2013. DOI: http://dx.doi.org/10.30969/acsa.v9i4.400

PLÁ, R. G.; Análise integrada do uso e aptidão agrícola dos solos na Amazônia Legal visando o desenvolvimento sustentável. 2011. 82f. Dissertação (Mestrado), Universidade Católica do Rio Grande do Sul, Porto Alegre, 2011.

RAMALHO FILHO, A.; BEEK, K. J. Sistema de avaliação da aptidão agrícola das terras. 3. ed. Rio de Janeiro: EMBRAPA/CNPS, $1995.65 \mathrm{p}$.

RAMPIM, L.; TAVARES, F. J.; BEHLAU, F.; ROMANO, D. Determinação da Capacidade de Uso do Solo visando o Manejo Sustentável para uma média propriedade em Londrina-PR. Bioscience Journal, Uberlandia, v. 28, n. 2, p. 251-264, 2012.

RAUBER, L. P.; PICCOLLA, C. D.; ANDRADE, A. P.; FRIEDERICHS, A.; MAFRA, A L.; CORRÊA, J. C.; ALBUQUERQUE, J. A. Physical properties and organic carbon content of a Rhodic Kandiudox fertilized with pig slurry and poultry litter. Revista Brasileira de Ciência do Solo, Viçosa, v. 36, n. 4, ago. 2012. DOI: http://dx.doi.org/10.1590/S0100-06832012000400026 